\title{
A fluorescent biosensor based on quantum dot-labeled streptavidin and poly-L-lysine for the rapid detection of Salmonella in milk
}

\author{
Shuangyan Ding, ${ }^{1}$ Hailiang Hu, ${ }_{1}$ Xianglin Yue, ${ }^{1}$ Kaiwen Feng, ${ }^{1}$ Xiaoyu Gao,,${ }^{1}$ Qiuling Dong, ${ }^{1}$ Mingqi Yang, ${ }^{1}$ \\ Ugur Tamer, ${ }^{2} \odot$ Ganhui Huang, ${ }^{1} \odot$ and Jinsheng Zhang ${ }^{1 *} \oplus$ \\ ${ }^{1}$ State Key Laboratory of Food Science and Technology, Nanchang University, Nanchang 330047, P. R. China \\ ${ }^{2}$ Department of Analytical Chemistry, Faculty of Pharmacy, Gazi University, 06500, Ankara, Turkey
}

\begin{abstract}
Salmonella, as a common foodborne pathogen in dairy products, poses a great threat to human health. We studied a new detection method based on quantum dots (QD). A fluorescent biosensor with multiple fluorescent signal amplification based on a streptavidin (SA) biotin system and the polyamino linear polymer poly-L-lysine (PLL) were established to detect Salmonella in milk. First, Salmonella was captured on a black 96-well plate with paired Salmonella mAb to form a double-antibody sandwich. Second, SA was immobilized on biotin-modified $\mathrm{mAb}$ by SA-biotin specific bond. Then, the biotinmodified polylysine (BT-PLL) was bound on SA and specifically bonded again through the SA-biotin system. Finally, water-soluble CdSe/ZnS QD-labeled SA was added to a black 96-well plate for covalent coupling with BT-PLL. The fluorescent signal was amplified in a dendritic manner by the layer-by-layer overlap of SA and biotin and the covalent coupling of biotinylated PLL. Under optimal conditions, the detection limit was $4.9 \times 10^{3} \mathrm{cfu} / \mathrm{mL}$ in PBS. The detection limit was 10 times better than that of the conventional sandwich ELISA. In addition, the proposed biosensor was well specific and could be used for detecting Salmonella in milk samples.
\end{abstract}

Key words: quantum dots, milk, Salmonella, fluorescence

\section{INTRODUCTION}

Salmonella is a pathogenic bacterium with over 2,500 serotypes identified that can cause zoonotic diseases (Foley and Lynne, 2008; Liébana et al., 2009); it is widely distributed in nature. Salmonella Anatum is one of the serotypes of Salmonella. Since Salmonella Ana-

Received September 1, 2021.

Accepted December 20, 2021.

*Corresponding author: zhangjinsheng@ncu.edu.cn tum was first identified as causing infection in human infants (1948), it has become an important zoonotic pathogen and has caused widespread outbreaks (Hartmann and West, 1995; Singh et al., 2010). Its effect on human health and safety is greater than other foodborne pathogens (Wu et al., 2021) because it is commonly present in human food and animal-derived food (e.g., milk, meat, and eggs). Milk is an important part of the human diet. However, because it contains different nutrients (Zhou et al., 2017; Murasova et al., 2020), milk is the best medium for the growth and proliferation of various bacteria (Angela et al., 2006; Bano, 2020). Drinking milk contaminated with Salmonella can easily cause abdominal pain, diarrhea, acute gastroenteritis, and even death (Ni et al., 2018; Wang et al., 2018). Therefore, an accurate, simple, and efficient method for detecting Salmonella in milk should be established.

Established techniques for determining Salmonella include bacterial culture, PCR (Kubo et al., 2020), loop-mediated isothermal amplification (Chen et al., 2015b; Wen et al., 2020), and immunofluorescence detection (Yang et al., 2018; Yu et al., 2019). Bacterial culture, which is a gold standard method for detecting bacteria, has high accuracy but is time consuming and labor intensive (Yu and Stopa, 1996; Majdinasab et al., 2018; Xiong et al., 2019). The PCR method is sensitive and specific (Chhalliyil et al., 2020) but requires skilled technicians and expensive instruments (Tsen et al., 2013; Yu et al., 2019). High requirements for pretreating food samples can easily result in false negatives (Mercanoglu Taban et al., 2009). Loop-mediated isothermal amplification has high sensitivity and short response time (Fan et al., 2015) but is susceptible to aerosol contamination. This process is also dependent on unobvious turbidity, and color changes may lead to false-negative results (Kaewphinit et al., 2013; Momin et al., 2020).

Recently, with the advancement of nanomaterial technology and biotechnology, various biosensors for detecting pathogenic bacteria have been developed, including optical (Wang et al., 2020), magnetic (Chen 
et al., 2015a; Qi et al., 2021), and electrochemical (Feng et al., 2021). As an important part of the optical sensor, the fluorescence sensor has many advantages including simple operation, high sensitivity, fast speed, and easy readout (Xue et al., 2018). Furthermore, the fluorescent label is very important for the detection performance of the fluorescence sensor. Among different fluorescent labels, quantum dots (QD) have been widely used in fluorescence sensors because of their high stability and high fluorescence performance (Chen et al., 2019). Fluorescence technology relies on the output of light signal when the target has been identified and labeled by the probe. The presence of more targets indicates more labeling by the probe and greater output light signal. The realization of the high sensitivity of the fluorescence immunoassay technology mainly depends on the amplification of the fluorescence signal (Wu et al., 2020b). Currently, many methods have been proposed based on fluorescence signal amplification strategies, including rolling circle amplification (Zhang et al., 2018b; Xiao et al., 2020), silver nanocluster amplification (Zhang et al., 2021), polymerization-induced nanobeads (Wu et al., 2020b), and nucleic acid fragment amplification (Liu et al., 2016; Yu et al., 2019). However, few studies have been done on the amplification of fluorescent signals based on polymer and streptavidin-biotin systems.

In this study, Salmonella Anatum was used as the research model, a fluorescent sensor using polyamino linear polymer poly-L-lysine (PLL) macromolecule as the probe skeleton, water-soluble QD as fluorescent probes, and the streptavidin-biotin system was applied for rapidly detecting Salmonella in milk. The watersoluble QD (PEGylated, CdSe/ZnS/-COOH) used in this study enabled the synthesized QD-SA fluorescent probes to maintain high stability and reduced nonspecific adsorption (Bentzen et al., 2005; Zhang et al., 2018a). The PLL is a linear polymer containing many amino groups and can be used as a multifunctional molecular carrier. Several studies have been reported that the covalent modification of PLL on its surface can increase the loading of probes (Zou et al., 2019; Wu et al., 2020a). Thus, to enhance the output fluorescent signal and identify more targets, PLL were introduced in the proposed biosensor to load more fluorescent probes. If the PLL macromolecules are directly modified on the surface of QD, cross-linking PLL and QD can be easily carried out. Thus, the QD become abnormally large and agglomerate because PLL is very large. Therefore, PLL was selected for covalent coupling with biotin. The PLL contains a large number of amino sites. After coupling with biotin, the PLL can amplify biotin. In addition, the SA-biotin system has also been introduced into fluorescent sensors to improve sensitivity. One molecule of biotin can bind to 4 molecules of biotin through high affinity (Yue et al., 2021). Biotin based on polymer amplification can be combined with more fluorescent probes (QD-SA) through the SA-biotin system, facilitating the loading of more fluorescent markers on the surface of PLL to a certain extent. Meanwhile, PLL can also use SA as a bridge to bind more biotin-modified monoclonal antibody (BT-mAb) to amplify signals to recognize more target bacteria, thereby increasing the sensitivity of detection. In general, the amplification strategy of using polymer-amplified biotin to achieve fluorescence signal is based on the signal amplification of particles. Compared with a single fluorescent probe, the fluorescence signal is amplified as a whole in this method.

We amplified multiple fluorescent signals during the detection process by synthesizing QD-SA probes, biotin-modified polylysine (BT-PLL), and overlapping SA and biotin layers to form the dendrite structure $\left(\mathrm{BT}^{*} \mathrm{mAb}-\mathrm{SA}-\mathrm{BT}{ }^{*} \mathrm{PLL}-\mathrm{QD} * \mathrm{SA} ; \quad *\right.$ indicates amide bond). A schematic diagram of the detection process is shown in Figure 1(C). We first used the high specificity of the mAb to capture Salmonella in black 96-well plates. Then, we modified the SA on the BT-mAb and the BT-PLL on the SA. Finally, we attached the QDSA fluorescent probes to BT-PLL to form dendritic structures. Thus, through the layer-by-layer overlapping of SA and biotin and multiple-loaded fluorescent label of PLL, we achieved multiple amplification of the signal to lower the detection limit (LOD) and made the detection more sensitive.

\section{MATERIALS AND METHODS}

\section{Materials and Reagents}

1-Ethyl-3-(3-dimethylaminopropyl) carbodiimide (EDC. $\mathbf{H C l}$ ) and N-hydroxysuccinimide sodium salt (NHSS) were provided by Aladdin. Water-soluble CdSe/ZnS QD (item no. Q3605, PEG/-COOH) were obtained from Wuhan Jiayuan Quantum Dot Technology Company. The PLL hydrobromide (30-70 kDa) was supplied by Sigma-Aldrich. The SA was provided by the Shanghai Hualan Technology Company. Bovine serum albumin, agarose, horseradish peroxidase-labeled SA (HRP-SA), and chromogenic fluid (tetramethylbenzidine and $\mathrm{H}_{2} \mathrm{O}_{2}$ ) were purchased from Solarbio Science Company. In addition, (+)-biotin N-hydroxysuccinimide ester (BT) was purchased from Thermo Fisher Scientific. Paired Salmonella mAb were obtained from Alpha Lifetech Co. The mAb is specific to the following Salmonella species: Salmonella Typhi A, Salmonella Agona, Salmonella Typhimurium, Salmonella Paratyphi B, Salmonella Thompson, Salmonella Blockley, Salmonella Kentucky (C3), Salmonella Enter- 
itidis, Salmonella Typhi, Salmonella Dublin, Salmonella Anatum, and Salmonella Arizonae. Pasteurized milk was bought at a convenience store (Meiyijia, Jiangxi, China). Carbon film copper mesh (300 mesh) was purchased from Zhongjing Science \& Instrument Co. Ltd.

\section{Equipment}

A multifunctional reader Varioskan LUX microplate was obtained from Thermo Fisher Scientific Company. In addition, a 96-well black polystyrene plate and 96well transparent microtiter plate were purchased from Corning Co. The refrigerated centrifuge was supplied by Eppendorf. The particle size of the QD-SA complex and the zeta potential of BT-PLL were measured by a Zetasizer Nano ZS90. Agarose gel electrophoresis of the QD-SA image was performed in a Chemi Doc
MP imaging system (Bio-Rad). Transmission electron microscopy (TEM) images of the QD and QD-SA were obtained by the JEM-2100 transmission electron microscope (JEOL Ltd.). Agarose gel electrophoresis of QD-SA was measured by DYY-6C Electrophoresis system (Bio-Rad).

\section{Bacteria Culture Conditions and Counting}

We used Salmonella Anatum (ATCC 9270) in this study as target bacteria, and Shigella sonnei (Jiangxi CDC isolates), Escherichia coli O157:H7 (CMCC 44102), Listeria monocytogenes (ATCC 19115), Pseudomonas aeruginosa (CMCC 11997), and Staphylococcus aureus (CMCC, 2603) were used as nontarget bacteria in the experiments. These strains were inoculated in Luria-Bertani medium and cultured at $37^{\circ} \mathrm{C}$ for 14 to
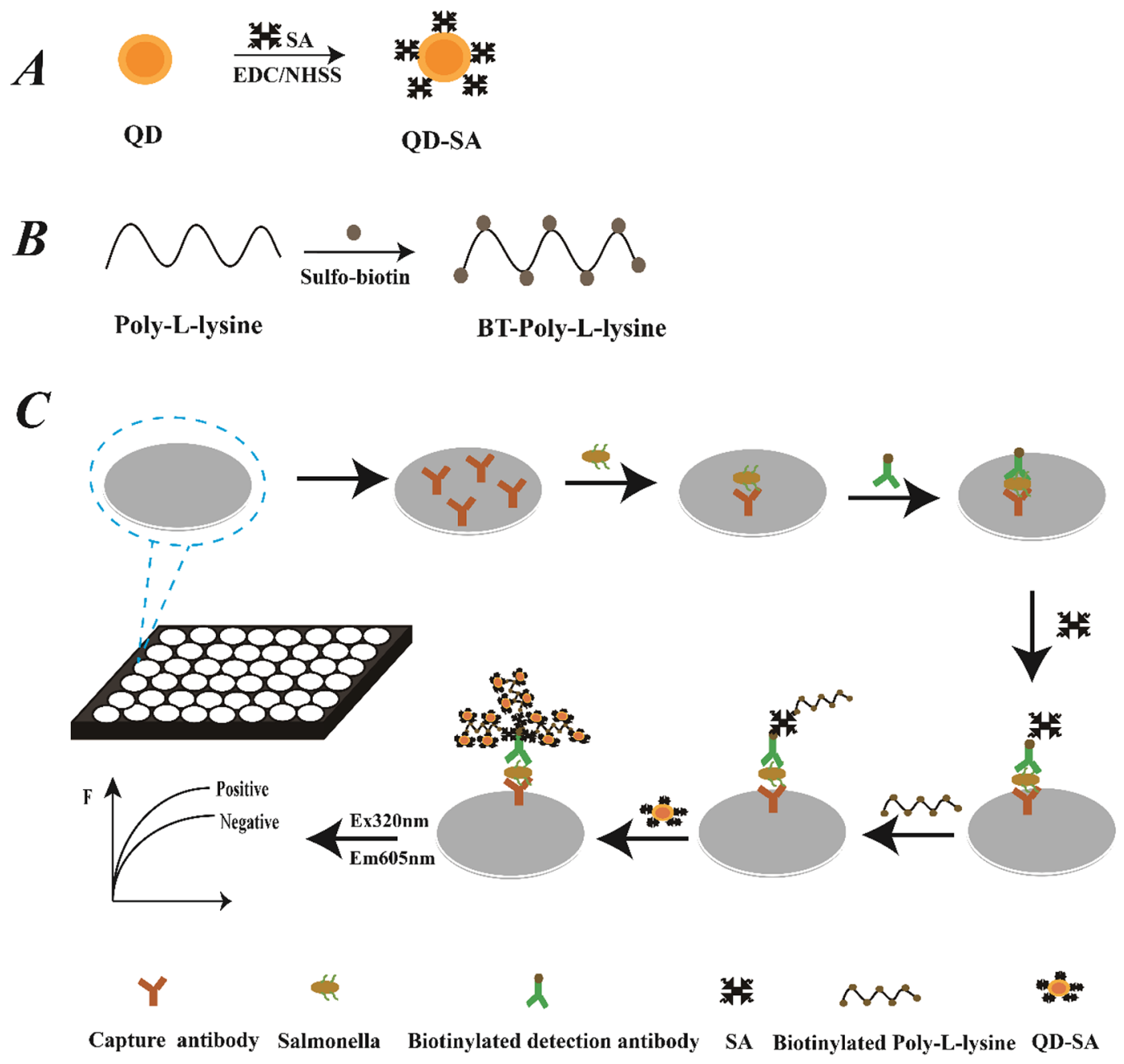

Figure 1. Detection of Salmonella by fluorescence sensor: (A) the preparation of quantum dot (QD)-streptavidin (SA), (B) the preparation of biotin-modified polylysine (BT-PLL), and (C) the fluorescence detection assay for detection of Salmonella in milk. EDC = 1-ethyl-3-(3dimethylaminopropyl) carbodiimide; NHSS = N-hydroxysuccinimide sodium salt; Ex = excitation (wavelength); Em $=$ emission $($ wavelength). 
$18 \mathrm{~h}$ in a shaker incubator and then cultivated for 18 to $20 \mathrm{~h}$ on agar solid medium for plate counting. The results of plate counting were expressed as colonyforming units. After the experiment, all experimental strains were sterilized in a sterilization pot at $121^{\circ} \mathrm{C}$ for $30 \mathrm{~min}$ for the safety of the laboratory.

\section{Synthesis of QD-SA}

A synthesis schematic diagram of QD-SA is shown in Figure 1(A). The QD-SA was prepared according to the methods of Shao et al. (2018) with slight modifications. The molar ratio of $\mathrm{QD} / \mathrm{EDC} / \mathrm{NHSS} / \mathrm{SA}$ was 1:2,000:1,000:20. First, the QD were diluted to $1 \mu M$ with $0.01 M$ sterile borate buffer solution (BBS, pH 7.4), and then $15 \mu \mathrm{L}$ of freshly prepared $\mathrm{EDC}(5 \mathrm{mg} / \mathrm{mL}$ in BBS) and $6.96 \mu \mathrm{L}$ of freshly prepared NHSS $(5 \mathrm{mg} /$ $\mathrm{mL}$ in $\mathrm{BBS}$ ) were added in sequence. These mixtures were gently mixed at room temperature for $30 \mathrm{~min}$ to activate the carboxyl groups on the surface of the QD. Then, SA was added to the mixture and mixed for 2 $\mathrm{h}$ at room temperature. After mixing for $2 \mathrm{~h}, 1 \%$ (wt/ vol) BSA was used to block unreacted carboxyl groups on QD. Then, the reacted mixture was centrifuged at $10,000 \times g$ for $3 \mathrm{~min}$ at room temperature to remove possible agglomeration. Then, a $100-\mathrm{kDa}$ ultrafiltration membrane was used to centrifuge at $8,000 \times g$ at room temperature for $5 \mathrm{~min}$ to remove excess SA. After 5 consecutive centrifugations, purified and concentrated QD-SA was collected in a low adsorption centrifuge tube, and then the collected purified and concentrated QD-SA was stored at $4^{\circ} \mathrm{C}$ in the dark for future use.

\section{Characterization of QD-SA by Agarose Gel Electrophoresis}

The electrophoretic mobility of agarose gel electrophoresis can determine the successful synthesis of QD-SA. The first step was the preparation of $0.5 \%$ wt agarose gel $(0.3 \mathrm{~g}$ of agarose dissolved in $60 \mathrm{~mL}$ of $1 \times$ Tris-acetate-EDTA buffer). Then the side of the gel with the sample well was placed on the negative electrode of the electrophoresis tank. The sample well in the gel was added with $10 \mu \mathrm{L}$ of $1 \mu M \mathrm{QD}$, physical mixture of QD and SA, and QD-SA, respectively. The parameters of the electrophoresis instrument were set at $90 \mathrm{~V}$ for $50 \mathrm{~min}$. When the electrophoresis was completed, the gel was analyzed using a Chemi Doc MP imaging system, and then bands appeared.

\section{Synthesis of $B T-m A b$ and $B T-P L L$}

The synthesis of BT-mAb had been reported in a previous study (Jin et al., 2020; Li et al., 2020) and was slightly modified. The active esterified biotin was reacted with the antibody at a molar ratio of 20:1. The coupling reaction, which was carried out in a sterilized centrifuge tube for coupling reaction wrapped in foil, was continuously stirred at $32 \mathrm{rpm}$ for $2 \mathrm{~h}$ at room temperature. After the complete reaction, the mixture was centrifuged $\left(8,000 \times g\right.$ for $5 \mathrm{~min}$ at $\left.4^{\circ} \mathrm{C}\right) 5$ times to remove excess biotin. The purified BT-mAb was collected after centrifugation, mixed with an equal volume of sterile glycerin, and stored at $-20^{\circ} \mathrm{C}$.

The BT-PLL was prepared according to the methods of Chirra et al. (2011) with slight modifications [Figure 1(B)]. First, $50 \mu \mathrm{L}$ of PLL $(2 \mathrm{mg} / \mathrm{mL}$ in sodium bicarbonate buffer) in $0.01 M$ PBS was mixed with 3.96 $\mu \mathrm{L}$ of freshly prepared active esterified biotin (1 mg of esterified biotin in $180 \mu \mathrm{L}$ of ultrapure water). The mixture was incubated for $45 \mathrm{~min}$ at room temperature. After the reaction, unreacted and excess biotin of the mixture was removed through centrifugation 5 times $\left(8,000 \times g, 8^{\circ} \mathrm{C}, 5 \mathrm{~min}\right)$. After 5 centrifugation steps, the purified BT-PLL was collected and stored at $4^{\circ} \mathrm{C}$.

\section{Fluorescence Immunosorbent Assay}

A schematic diagram of the fluorescence immunosensor is shown in Figure 1(C). First, the Salmonella capture antibody was resuspended to $2.5 \mu \mathrm{g} / \mathrm{mL}$ with $0.01 M$ PBS. Then, $100 \mu \mathrm{L}$ of this antibody $(2.5 \mu \mathrm{g} /$ $\mathrm{mL}$ ) was coated on black 96-well plates and incubated at $4^{\circ} \mathrm{C}$ overnight. The antibody that was not fixed on the black 96-well plate was washed thrice with 0.01 $M$ PBST (pH 7.4, containing 0.05\% Tween 20) and spin-dried. The nonspecific binding sites were blocked with $1 \%$ (wt/vol) BSA $(200 \mu \mathrm{L} /$ well $)$ at $37^{\circ} \mathrm{C}$ for $2 \mathrm{~h}$. Then the black 96 -well plate was washed thrice with $0.01 M$ PBST and spin-dried. A 10-fold gradient of the Salmonella solution $\left(10^{1}-10^{7} \mathrm{cfu} / \mathrm{mL}, 100 \mu \mathrm{L} /\right.$ well $)$ was used as the positive group. The negative group (100 $\mu \mathrm{L} /$ well) was added with sterile PBS and incubated at $37^{\circ} \mathrm{C}$ for $1 \mathrm{~h}$. After the black 96-well plate was washed thrice with $0.01 M$ PBST, $100 \mu \mathrm{L}$ of $0.625,1.25,2.5,5$, $7.5,10,12.5 \mu \mathrm{g} / \mathrm{mL}$ BT-mAb was added to each well and incubated at $37^{\circ} \mathrm{C}$ for $1 \mathrm{~h}$. The black 96-well plate was washed 4 times. Then, $100 \mu \mathrm{L}$ of SA was added to each well and incubated for $30 \mathrm{~min}$ at $37^{\circ} \mathrm{C}$. The black 96-well plate was washed 4 times. Then, $100 \mu \mathrm{L}$ of BTPLL (molar ratio of SA:BT-PLL of $2: 1,2: 3,2: 5,2: 7$, $2: 9,2: 11$, and $2: 13$ ) was added to the black 96 -well plate and incubated for $30 \mathrm{~min}$ at $37^{\circ} \mathrm{C}$. The black 96-well plate was washed 5 times. Finally, $100 \mu \mathrm{L}$ of QD-SA (molar ratio of QD:SA of 1:5, 1:10, 1:15, 1:20, and 1:25; 1:100 dilution) was added to the black 96-well plate and incubated for $30 \mathrm{~min}$ at $37^{\circ} \mathrm{C}$. The black 96-well plate was washed thrice and spin-dried. The fluorescent 
signal from the immune complexes (excitation wavelength, $320 \mathrm{~nm}$; emission wavelength, $605 \mathrm{~nm}$ ) from the dried plates was directly read using the multifunctional microplate reader. The relative increase in fluorescence signal $\left(\mathrm{F} / \mathrm{F}_{0}\right)$ was determined as follows:

$$
\mathrm{F} / \mathrm{F}_{0}=\mathrm{F}_{1}-\mathrm{F}_{\text {blank }} / \mathrm{F}_{2}-\mathrm{F}_{\text {blank }},
$$

where $F_{1}$ and $F_{2}$ are the fluorescence intensities of the immune complex on the plate with and without Salmonella, respectively, and $\mathrm{F}_{\text {blank }}$ is the fluorescence intensity of the blank reagent.

The LOD of the method was calculated as LOD = $\mathrm{M}+3 \times \mathrm{SD}$, where $\mathrm{M}$ is the fluorescence intensity of the negative control groups, and SD is the standard deviation of these groups (Duan et al., 2021).

\section{Traditional ELISA Calibration Curve}

The traditional ELISA method was performed according to the method of Guo et al. (2016) with slight modifications. Salmonella capture antibody $(2.5 \mu \mathrm{g} /$ $\mathrm{mL}, 100 \mu \mathrm{L} /$ well) was coated onto 96-well polystyrene plate at $4{ }^{\circ} \mathrm{C}$ overnight. After washing the 96 -well plate twice with $300 \mu \mathrm{L}$ of $0.01 M$ PBST, $1 \%$ (wt/ vol) BSA blocking buffer $(200 \mu \mathrm{L} /$ well $)$ was added to 96-well plate and incubated at $37^{\circ} \mathrm{C}$ for $2 \mathrm{~h}$ to block unspecific binding sites. After washing thrice, $100 \mu \mathrm{L}$ of the diluted bacterial solution $\left(10^{1}-10^{7} \mathrm{cfu} / \mathrm{mL}\right)$ was added into the positive well and incubated in a 96-well plate for $1 \mathrm{~h}$ at $37^{\circ} \mathrm{C}$. Sterile PBS $(100 \mu \mathrm{L} /$ well $)$ was added to the negative well as a control. The 96-well plate was washed thrice with $0.01 \mathrm{M}$ PBST, and biotinylated anti-Salmonella mAb $(2.5 \mu \mathrm{g} / \mathrm{mL}, 100 \mu \mathrm{L} /$ well) was added into 96-well plate and incubated for 1 $\mathrm{h}$ at $37^{\circ} \mathrm{C}$. The 96 -well plate was washed 5 times with $0.01 M$ PBST. The HRP-SA [diluted 5,000 times with $0.01 M$ PBS $(100 \mu \mathrm{L} /$ well $)]$ was added to the 96 -well plate. After the 96 -well plate were incubated at $37^{\circ} \mathrm{C}$ for $45 \mathrm{~min}$ and washed 7 times with $0.01 \mathrm{M}$ PBST, tetramethylbenzidine $/ \mathrm{H}_{2} \mathrm{O}_{2}(100 \mu \mathrm{L} /$ well $)$ was added and incubated at $37^{\circ} \mathrm{C}$ for $15 \mathrm{~min}$. Then, $50 \mu \mathrm{L}$ of 2 $M \mathrm{H}_{2} \mathrm{SO}_{4}$ was added to stop the reaction, and the 96well plate was placed in the multifunctional microplate reader. The wavelength was adjusted to $450 \mathrm{~nm}$ to read the absorbance. All of the experimental data came from 3 parallel tests.

\section{Specific Detection}

We selected Salmonella and 5 other nontargeted strains (Shigella sonnei, Escherichia coli O157:H7, Listeria monocytogenes, Pseudomonas aeruginosa, and Staphylococcus aureus) to assess the specificity of the proposed method under optimized conditions, and the concentration of Salmonella and 5 other nontargeted strains $\left(10^{8} \mathrm{cfu} / \mathrm{mL}\right)$ was calculated by plate counting. The concentration of all experiment strains was diluted to $10^{7} \mathrm{cfu} / \mathrm{mL}$ in sterile PBS. Sterile PBS was used as a negative control. All of the experimental data came from 3 parallel tests.

\section{Sensitivity Detection of Salmonella in Whole Milk}

Salmonella at a concentration of $4.9 \times 10^{8} \mathrm{cfu} / \mathrm{mL}$ was added to sterile whole milk; then, the spiked milk was serially diluted to make concentrations of $4.9 \times$ $10^{1}, 4.9 \times 10^{2}, 4.9 \times 10^{3}, 4.9 \times 10^{4}, 4.9 \times 10^{5}, 4.9 \times$ $10^{6}$, and $4.9 \times 10^{7} \mathrm{cfu} / \mathrm{mL}$. The concentration of Salmonella was calculated by plate counting. Milk without Salmonella was used as the negative control. All of the experimental data came from 3 parallel tests.

\section{Data Analysis}

All of the experimental data were obtained from 3 parallel tests. Version 19 SPSS (SPSS Inc.) was used to perform final statistics and analysis.

\section{RESULTS AND DISCUSSION}

\section{Characterization of QD-SA}

Optical Properties Analysis. The QD and QDSA were scanned with a multifunctional microplate reader to determine their emission wavelengths. The fluorescence spectra of QD and QD-SA were measured at an excitation wavelength of $320 \mathrm{~nm}$ and an emission wavelength range of 505 to $705 \mathrm{~nm}$. Figure 2(A) shows the original QD had maximum fluorescence intensity at $605 \mathrm{~nm}$. After being covalently coupled with SA, it retained its maximum fluorescence intensity at 605 $\mathrm{nm}$. In addition, the fluorescence intensity of the QD$\mathrm{SA}$ is slightly lower than that of the $\mathrm{QD}$, which may be caused by the dilution and consumption of QD in the reaction process (Zhou et al., 2021). Therefore, no obvious shift was found in the maximum emission peak compared with that of the uncoupled QD. This result showed that the coupling of SA did not change the fluorescence properties of the QD.

Particle Size Analysis. The successful synthesis of QD-SA was verified according to the hydrated particle sizes of QD and QD-SA, agarose gel electrophoresis, and TEM. The results of the particle size are shown in the Figure 2(B). Dynamic light scattering analysis showed that the free QD had a particle size of $15 \mathrm{~nm}$. After the covalent coupling with SA, QD-SA was enlarged to $25 \mathrm{~nm}$. In addition, the particle size of the synthesized 
QD-SA was uniformly dispersed, and the small increase in particle size also indicated that no agglomeration occurred in the synthesized QD-SA, confirming the successful coupling of SA on the surface of the QD.

Agarose Gel Electrophoresis Analysis. Figure $2(\mathrm{C})$ shows 2 sets of parallel results of agarose gel electrophoresis before and after CdSe/ZnS QD was coupled with SA. Compared with the QD: lane 1, the physical mixture of QD and SA: lane 2 had no obvious change in migration distance, migration speed, and shape. By contrast, the QD-SA: lane 3 changed dramatically. First, its electrophoresis speed was slower than those of the lane 1 and the lane 2. Second, the migration distance became shorter. In addition, the lane 3 had a tailing phenomenon. These changes are related to the increase in the overall size and reduction of the surface negative charge caused by the covalent coupling of the QD and SA (Sahoo et al., 2019; Shandilya et al., 2021). Because SA was conjugated to the surface of the QD, the overall size of the coupling is larger than those of the QD without conjugation [Figure 2(B)]. In addition, SA and QD are coupled by an amide bond. Due to excessive SA, a large number of carboxyl groups were consumed on the surface of $\mathrm{QD}$, resulting in a decrease in the negative charge of the coupling. In the alkaline buffer system, negatively charged surface nanoparticles migrated from the negative electrode to the positive electrode (Yan et al., 2020a). Therefore, the migration
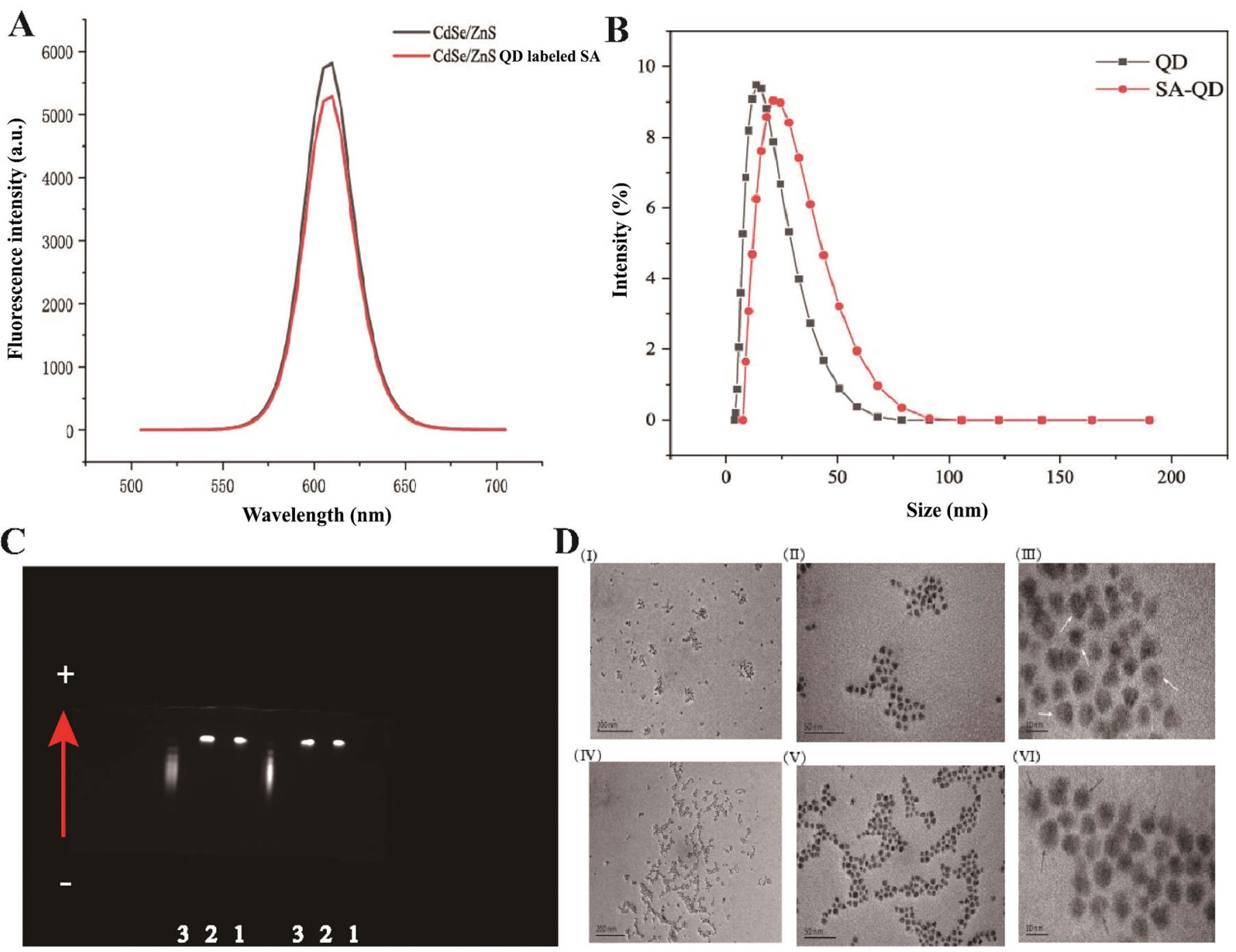

$\mathbf{D}_{(1)}$

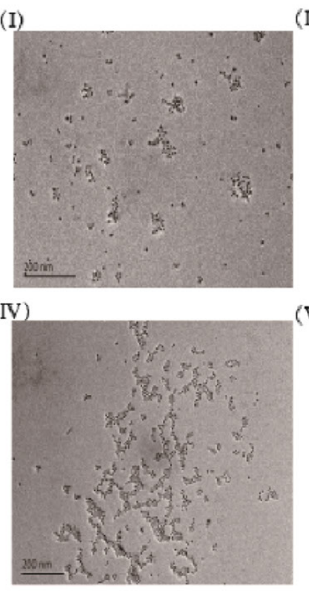

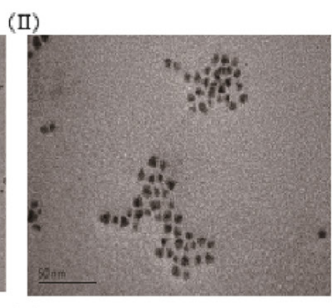
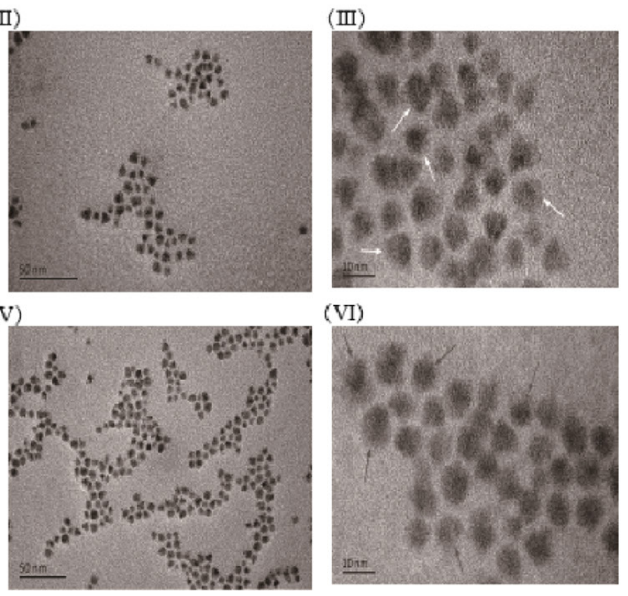

Figure 2. Characterization of quantum dot (QD)-streptavidin (SA): (A) fluorescence spectrum (a.u. = arbitrary units) of QD and QD-SA; (B) particle size of QD and QD-SA; (C) agarose gel electrophoresis of QD, physical coupling of SA and QD and QD-SA (the serial number is 1, 2, 3). (D) Transmission electron microscopy (TEM) image: (I), (II), and (III) are the TEM images of QD at 200, 50, and 10 nm, and (IV), (V), and (VI) are TEM images at 200, 50, and $10 \mathrm{~nm}$. The white and gray arrows are the selected representatives. Vertical bars represent SD $(\mathrm{n}=3)$. 
A

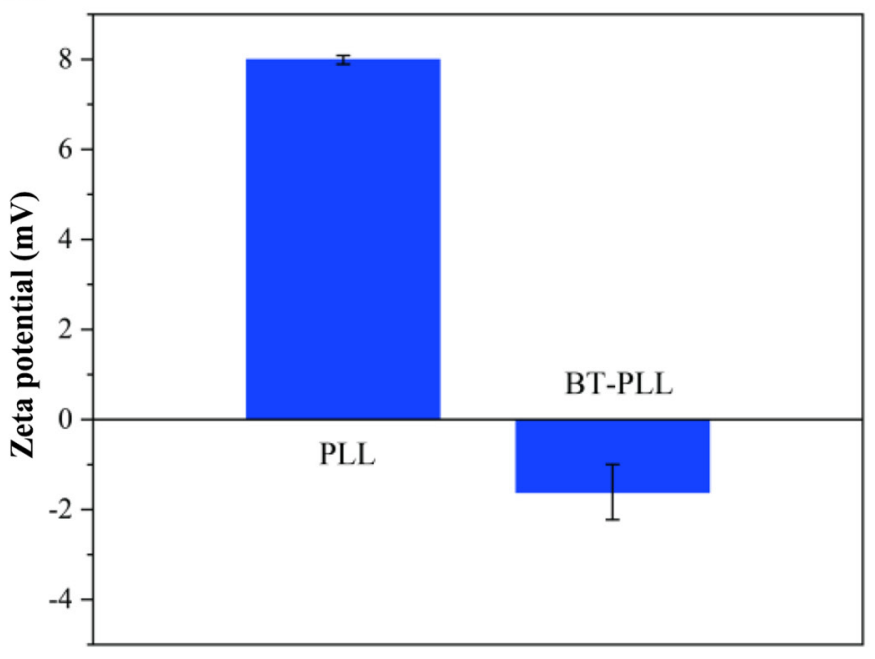

$\mathrm{B}$

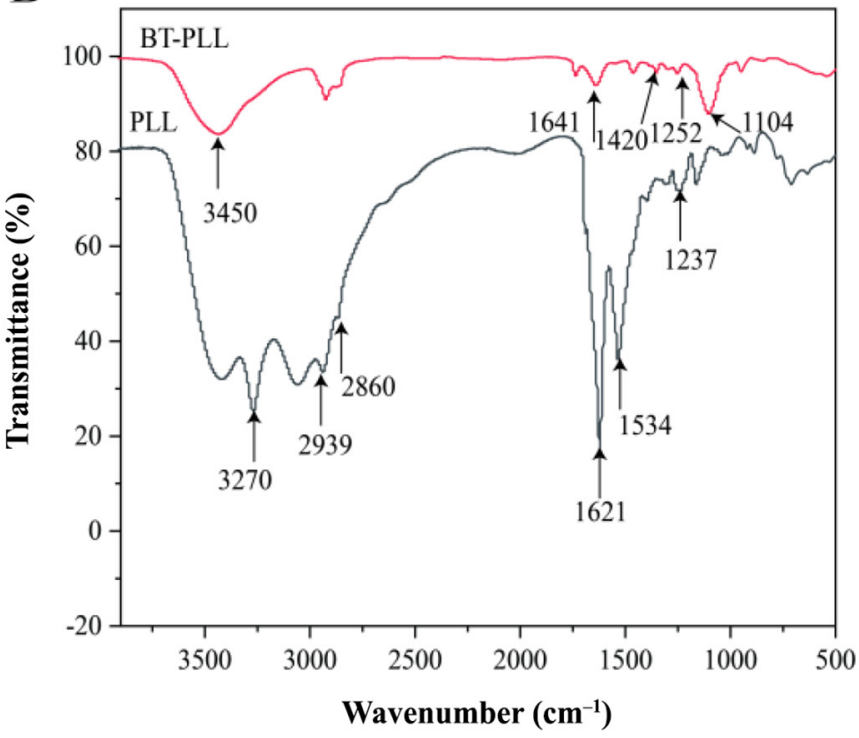

Figure 3. Characterization of biotin-modified poly-L-lysine (BT-PLL): (A) zeta potential of PLL and BT-PLL; (B) Fourier-transform infrared spectra of PLL and BT-PLL. The arrow indicates the position of the absorption peak. Vertical bars represent SD $(\mathrm{n}=3)$.

distance of the QD-SA in the gel is smaller than that of the QD and physical mixture of QD and SA. These results were consistent with a previous study (Zhang et al., 2017) on the functionalized QD probe, proving the successful coupling of the QD-SA probe.

TEM Analysis. The dispersion state, particle size, and lattice structure of the free $\mathrm{QD}$ and the QD marked with SA were evaluated by TEM to verify whether SA was successfully marked on the QD. As shown in Figure 2(D, IV-VI), the QD-SA was not agglomerated and was in a uniformly dispersed state. Similar phenomena have been reported in previous studies (Yan et al., 2020b). In Figure 2(D, III), the lattice structure of the QD was clear. In Figure 2(D, VI), the outermost lattice of QDSA structure was slightly fuzzy, which was related to the modification of SA on the QD. In addition, QD-SA was larger than the QD. These results demonstrated the successful coupling of the QD-SA probe.

\section{Characterization of BT-PLL}

Zeta Potential Analysis. To verify the successful synthesis of BT-PLL, we measured the zeta potential and Fourier-transform infrared spectra (FTIR) spectra of PLL and BT-PLL. The zeta potential of PLL was $+7.98 \pm 0.0971 \mathrm{mV}(\mathrm{n}=3)$ because the surface of PLL had numerous amino groups (Figure $3[\mathrm{~A}]$ ). After coupling with biotin, the zeta potential of BT-PLL decreased to $-1.61 \pm 0.6129 \mathrm{mV}(\mathrm{n}=3)$ because the formation of the amide bonds between biotin and PLL consumed the amino groups on the surface of PLL, thereby reducing the zeta potential of BT-PLL. Thus, the changes in zeta potential verified the successful connection of BT-PLL.

FTIR Analysis. The FTIR spectroscopy of PLL and BT-PLL is illustrated in Figure 3(B). The features of the BT-PLL spectrum at 1,641 and 1,462 $\mathrm{cm}^{-1}$ indicated the $\mathrm{C}-\mathrm{O}$ and $\mathrm{N}-\mathrm{H}$ vibrations, which were related to the formation of an amide bond (Shan et al., 2009). Given that biotin and PLL are coupled through an amide bond, $\mathrm{C}-\mathrm{O}$ stretching vibrations were observed at 1,104 and $1,252 \mathrm{~cm}^{-1}, \mathrm{C}-\mathrm{N}$ stretching vibration at $1,420 \mathrm{~cm}^{-1}$, and $\mathrm{N}-\mathrm{H}$ stretching vibration at $3,450 \mathrm{~cm}^{-1}$ (Ling et al., 2014). In addition, the absorption peak at $3,270 \mathrm{~cm}^{-1}$ on the FTIR spectrum of PLL was the amino absorption peak (characteristic peak of PLL; Dutta et al., 2020), but there was no absorption peak at 3,270 $\mathrm{cm}^{-1}$ on BT-PLL, which showed that the formation of amide bond consumes the amino group on PLL. These changes proved the successful coupling of BT-PLL.

\section{Optimization of Experimental Parameters}

To receive optimal effect of the method, we optimized the SA:QD synthesis molar ratio, concentration of biotinylated antibody, amount of BT-PLL, and QDSA incubation time.

Optimization of QD-SA Synthesis Molar Ratio. The concentration of Salmonella detected was $10^{7}$ $\mathrm{cfu} / \mathrm{mL}$. Figure 4(A) illustrates the influence of the synthesis ratio of QD-SA fluorescent probes on $\mathrm{F} / \mathrm{F}_{0}$. When the SA:QD molar ratio was from 5:1 to 20:1, 
A

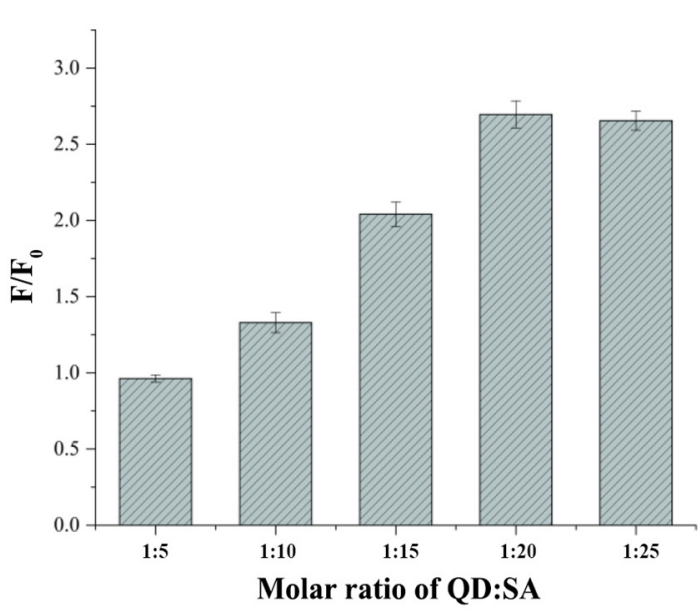

$\mathrm{C}$

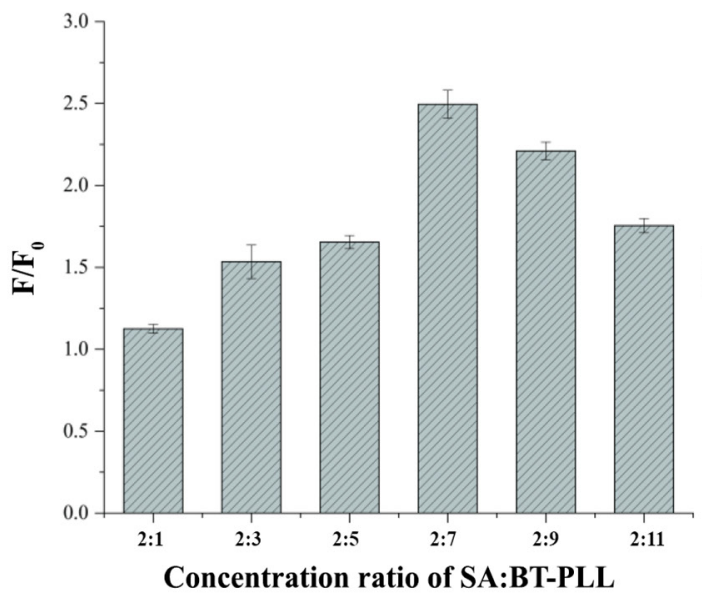

B

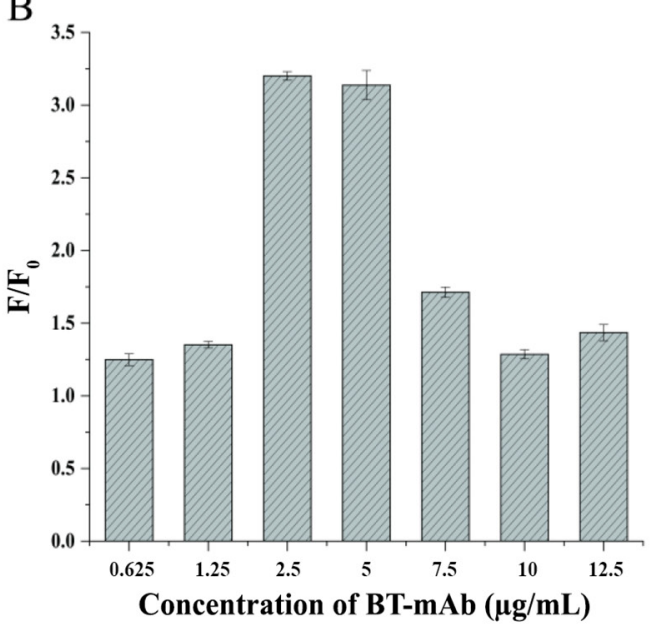

$\mathrm{D}$

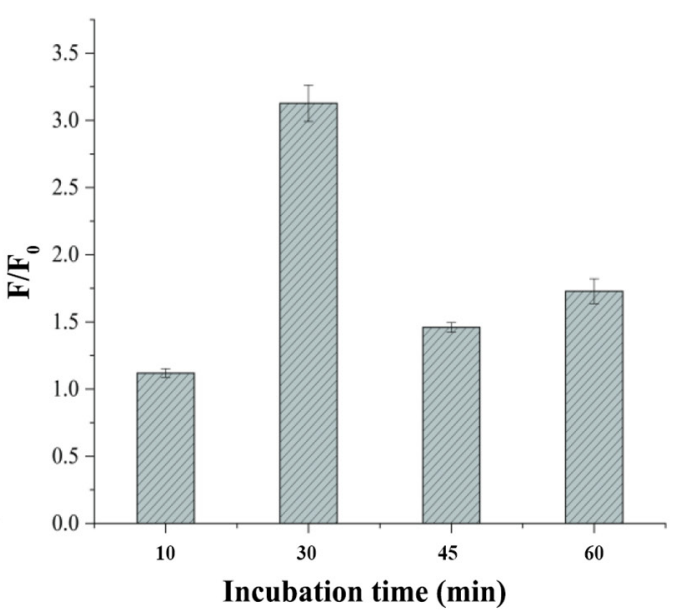

Figure 4. Optimization of the experimental parameters: (A) the concentration of quantum dot (QD)-streptavidin (SA) synthesis molar ratio, (B) the concentration of biotin-modified monoclonal antibody (BT-mAb) concentration, (C) biotin-modified polylysine (BT-PLL) concentration, and (D) the incubation time of the QD-SA fluorescent probe. $\mathrm{F} / \mathrm{F}_{0}$ represents the relative increase in fluorescence signal. Vertical bars represent $\mathrm{SD}(P<0.05, \mathrm{n}=3)$.

$\mathrm{F} / \mathrm{F}_{0}$ increased substantially. When the SA:QD molar ratio was $20: 1, \mathrm{~F} / \mathrm{F}_{0}$ reached its maximum value. When the molar ratio continued to increase, $\mathrm{F} / \mathrm{F}_{0}$ showed obvious change. To obtain the maximum $\mathrm{F} / \mathrm{F}_{0}$ and save the amount of $\mathrm{SA}$, we choose the $\mathrm{SA}: \mathrm{QD}$ synthetic molar ratio of 20:1.

Optimization of BT-mAb Concentration. Figure 4(B) shows the effect of QD-SA incubation time on $\mathrm{F} / \mathrm{F}_{0}$. When the concentration of BT-mAb increased from 0.625 to $2.5 \mu \mathrm{g} / \mathrm{mL}, \mathrm{F} / \mathrm{F}_{0}$ increased significantly. When the concentration of BT-mAb continued to increase, its $\mathrm{F} / \mathrm{F}_{0}$ decreased significantly. This phenomenon indicated that the orifice plate could only bind a certain amount of antibody. When the amount of antibody was excessive, the excessive BT-mAb competes with the antigen recognition site on the surface of Salmonella, leading to the failure of the reaction, which adversely affects the subsequent SA binding, thus reducing the probe marker amount and reducing the $\mathrm{F} / \mathrm{F}_{0}$. In addition, it can also lead to the hook effect (Li et al., 2018). Here, we selected the concentration of $\mathrm{BT}-\mathrm{mAb}$ at $2.5 \mu \mathrm{g} / \mathrm{mL}$.

Optimization of BT-PLL Concentration. Figure $4(\mathrm{C})$ shows the effect of SA-QD incubation time on $\mathrm{F} / \mathrm{F}_{0}$. When the concentration ratio of $\mathrm{SA}$ and $\mathrm{BT}$ PLL was increased from 2:1 to 2:7, its $\mathrm{F} / \mathrm{F}_{0}$ increased. The maximum $\mathrm{F} / \mathrm{F}_{0}$ (best value) was reached when the concentration ratio was $2: 7$. The amount of biotin on PLL was proportional to the fluorescence intensity in a certain concentration range. When the amount of biotin on PLL was beyond this range, the amount was not directly proportional to the fluorescence intensity. 
Optimization of QD-SA Fluorescent Probe Incubation Time. Figure 4(D) shows the effect of QD-SA incubation time on $\mathrm{F} / \mathrm{F}_{0}$. Incubation times of $10,30,45$, and 60 min were chosen. When the QD-SA incubation time in 96-well plate was increased from 10 to $30 \mathrm{~min}$, its $\mathrm{F} / \mathrm{F}_{0}$ significantly increased. However, continued increase in incubation time did not change $\mathrm{F} / \mathrm{F}_{0}$. To obtain the best effect and shorten the total experiment time, we chose $30 \mathrm{~min}$ as the best incubation time for the fluorescent probe.

\section{Results of Specificity}

To evaluate the specificity, Salmonella and 5 nonSalmonella strains were tested under optimal experimental conditions. The concentration of the 6 strains was $10^{7} \mathrm{cfu} / \mathrm{mL}$. Figure $5(\mathrm{~B})$ shows that the $\mathrm{F} / \mathrm{F}_{0}$ group that captured Salmonella was clearly higher than the other 5 non-Salmonella strains, which indicated that the fluorescence intensity of Salmonella group was significantly higher than that of the control group $(P$ $<0.05$ ), whereas the fluorescence intensity of other 5 non-Salmonella species was similar to the control group $(P>0.05)$. These results indicated the method had good specificity.

\section{Calibration Curve of Traditional ELISA for the Detection of Salmonella}

Under optimized conditions, calibration curves (Figure 5[A]) were established with known Salmonella concentrations and absorbance values. The linear range was $4.9 \times 10^{4}$ to $4.9 \times 10^{7} \mathrm{cfu} / \mathrm{mL}$. The linear equation was $\mathrm{y}=0.01834 \mathrm{x}-0.02194\left(\mathrm{R}^{2}=0.99148\right)$. When the concentration of Salmonella was $4.9 \times 10^{4}$, the absorbance value of the experimental group was slightly equal to the absorbance value corresponding to the LOD $[0.0978(\mathrm{~N}+3 \mathrm{SD})]$, where $\mathrm{N}$ is the mean of the negative group. Therefore, the LOD concentration of Salmonella was $4.9 \times 10^{4} \mathrm{cfu} / \mathrm{mL}$.

\section{Results of Sensitivity Detection in PBS Buffer and Whole Milk}

Under optimized conditions, the sensitivity of Salmonella in PBS was determined using this proposed method. Then the curve (Figure 6) of the Salmonella concentration and $\mathrm{F} / \mathrm{F}_{0}$ was established, and the linear range was $4.9 \times 10^{3}$ to $4.9 \times 10^{7} \mathrm{cfu} / \mathrm{mL}$ using the equation $\mathrm{F} / \mathrm{F}_{0}=0.4324 \log _{10}(\mathrm{~S})+0.0284$ with $\mathrm{R}^{2}=0.994$. When the Salmonella concentration was
A

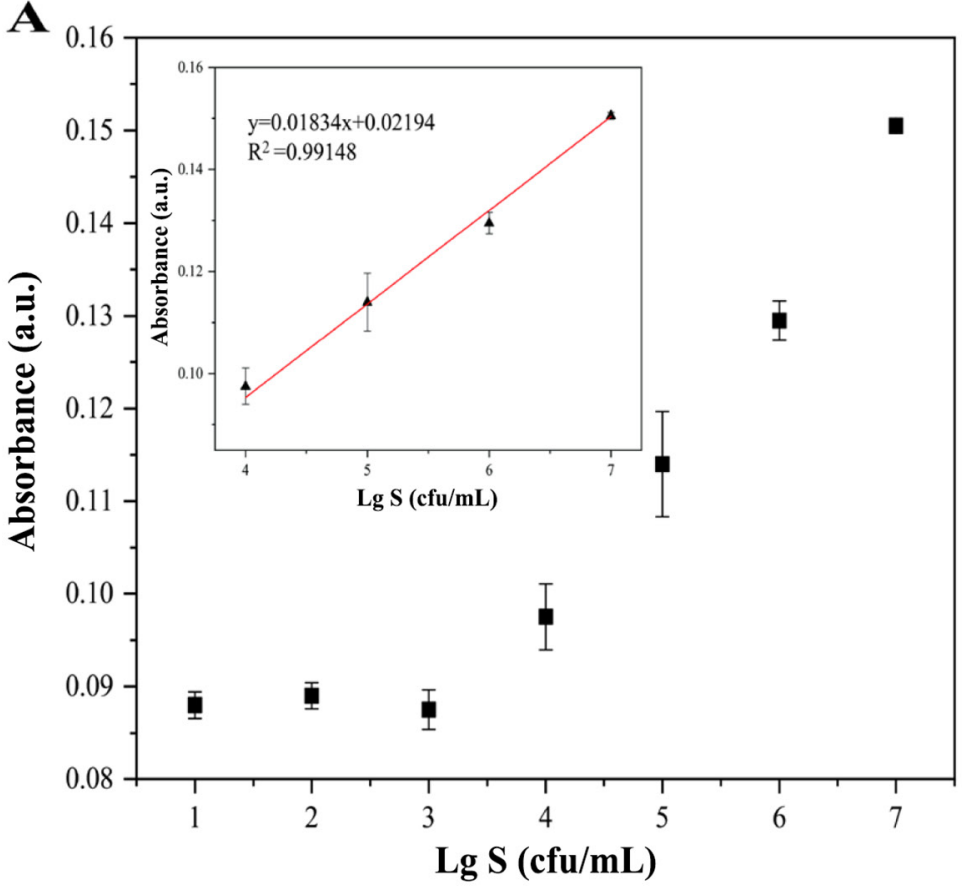

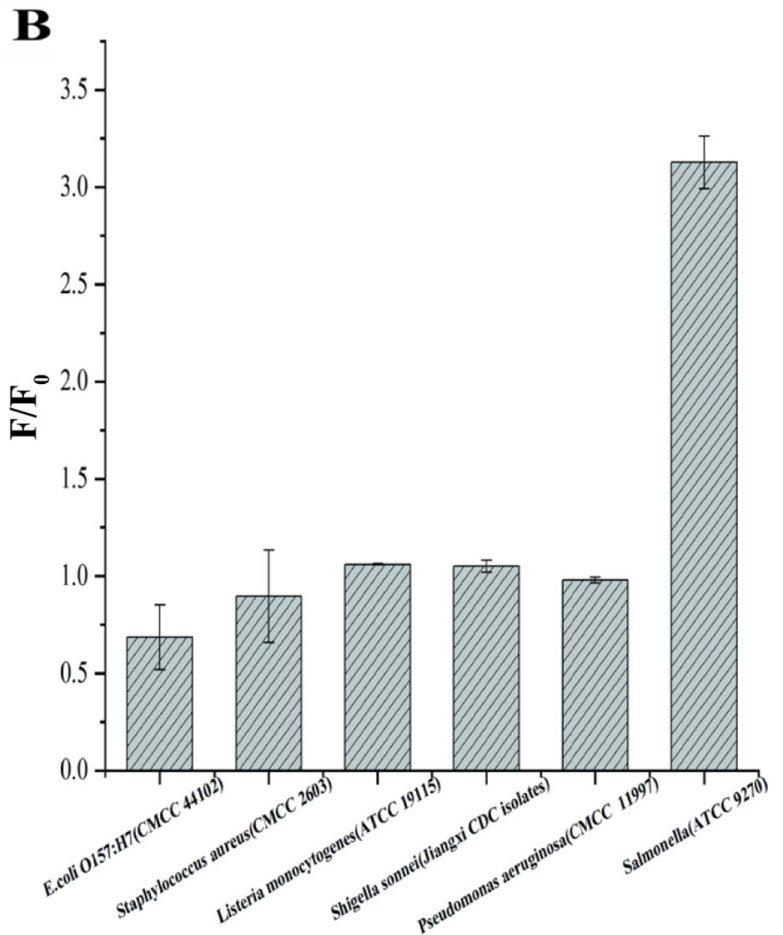

Figure 5. (A) Calibration curve of absorbance versus concentration of Salmonella from $4.9 \times 10^{1}$ to $4.9 \times 10^{7}$ cfu/mL and (B) specificity of fluorescence detection method for $10^{7} \mathrm{cfu} / \mathrm{mL}$ of Salmonella, Staphylococcus aureus, Listeria monocytogenes, Escherichia coli O157:H7, Shigella sonnei, and Pseudomonas aeruginosa. $\mathrm{F} / \mathrm{F}_{0}$ represents the relative increase in fluorescence signal. Vertical bars represent $\mathrm{SD}(P<0.05, \mathrm{n}=3)$. a.u. = absorbance units. 
Table 1. Detection results of Salmonella in the spiked milk samples ( $\mathrm{n}=3$ )

\begin{tabular}{llcccc}
\hline $\begin{array}{l}\text { Target } \\
\text { bacteria }\end{array}$ & Sample & $\begin{array}{c}\text { Plated count } \\
\text { method }(\mathrm{cfu} / \mathrm{mL})\end{array}$ & $\begin{array}{c}\text { Proposed method } \\
(\mathrm{cfu} / \mathrm{mL})\end{array}$ & $\begin{array}{c}\text { Recovery } \\
\text { rate }(\%)\end{array}$ & $\begin{array}{c}\mathrm{RSD}^{1} \\
(\%)\end{array}$ \\
\hline Salmonella & 1 & $4.9 \times 10^{4}$ & $4.12 \times 10^{4}$ & 84 & 9.28 \\
& 2 & $4.9 \times 10^{5}$ & $4.85 \times 10^{5}$ & 98 & 6.55 \\
& 3 & $4.9 \times 10^{7}$ & $5.63 \times 10^{7}$ & 114 & 9.14 \\
\hline
\end{tabular}

${ }^{1}$ RSD was defined as relative standard deviation divided by the mean and multiplied by 100 .

$4.9 \times 10^{3} \mathrm{cfu} / \mathrm{mL}$, the fluorescence intensity of the positive group was 0.1814 , which was slightly greater than that corresponding to the critical fluorescence intensity value of negative group of $0.1793174(\mathrm{~N}+$ 3SD), resulting in $\mathrm{F} / \mathrm{F}_{0}$ of 1.32855 . Therefore, the LOD concentration of Salmonella in the PBS buffer was 4.9 $\times 10^{3} \mathrm{cfu} / \mathrm{mL}$. The LOD of the proposed method was lower by 10 times compared with that of the traditional ELISA. In addition, the detection of Salmonella by using the PLL macromolecules coupled to QD via the SA-biotin system to amplify the fluorescence signal was more sensitive to a certain extent than using antibodies directly coupled to the surface of $\mathrm{QD}$ as fluorescent probes (Zhang et al., 2017). To further evaluate the applicability of the fluorescence sensor in actual samples, whole milk samples containing Salmonella concentration in the range of $4.9 \times 10^{1}$ to $4.9 \times 10^{7} \mathrm{cfu} / \mathrm{mL}$ were tested. As shown in Figure 6, the linear range of the standard curve is $4.9 \times 10^{4}$ to $4.9 \times 10^{7} \mathrm{cfu} / \mathrm{mL}$ using the equation of $\mathrm{F} / \mathrm{F}_{0}=0.39563 \log _{10}(\mathrm{~S})-0.00214$ with $\mathrm{R}^{2}=0.987$. Furthermore, LOD was determined by the mean value of background signal plus 3 times the mean standard deviation (Yu et al., 2019). Thus, the LOD concentration of Salmonella in the whole milk was 4.9 $\times 10^{4} \mathrm{cfu} / \mathrm{mL}$. The diverse results from the PBS buffer may be related to the failure to pretreat the whole milk sample. In addition, the concentrations of Salmonella in milk of $4.9 \times 10^{4}, 4.9 \times 10^{5}$, and $4.9 \times 10^{7} \mathrm{cfu} / \mathrm{mL}$ were measured by the proposed method. Experimental data came from 3 parallel groups. As shown in Table 1, the detection results of the proposed method were compared with the plate counting results. In addition, the recovery rate and RSD results of different concentration of Salmonella in milk indicate that this proposed method has great potential for detecting Salmonella in actual samples. Some methods for detecting Salmonella in milk have been reported in previous studies, but they have limitations, such as long detection time, high detection limits, complex operations, and the need for professional knowledge. Thus, the proposed method was compared with other methods for the detection of Salmonella (Mazumdar et al., 2007; Xu et al., 2015; Xia et al., 2016; Zou et al., 2019; Table 2). The LOD and detection time of the proposed fluorescence detection method were lower than those of the other detection methods.

\section{CONCLUSIONS}

We developed an accurate, simple, rapid, and efficient fluorescence immunoassay method. In our fluorescence detection sensor, we used paired Salmonella $\mathrm{mAb}$ and Salmonella target to form a double-antibody sandwich structure, resulting in a very specific sensor. The water-soluble carboxylated QD could maintain high stability and effectively reduce nonspecific adsorption after being covalently coupled with SA. In addition, SA had high affinity for biotin. One molecule of SA had 4 molecules of biotin binding sites, and the signal could be amplified by the SA-biotin system. The PLL as a macromolecule carrier could carry many fluorescent probes. Thus, we overlapped SA and biotin layer by layer and used PLL loaded with multiple fluorescent labels to form a dendritic structure to amplify the signal. The linear range detected by the proposed method was $4.9 \times 10^{3}$ to $4.9 \times 10^{7} \mathrm{cfu} / \mathrm{mL}$, and the LOD was $4.9 \times 10^{3} \mathrm{cfu} / \mathrm{mL}$. Therefore, the proposed method could accurately and quickly detect Salmonella

Table 2. Comparison of this method with other reported methods ${ }^{1}$

\begin{tabular}{llccl}
\hline Detection method & Sample & $\begin{array}{c}\text { Detection } \\
\text { time }(\mathrm{h})\end{array}$ & $\begin{array}{c}\text { LOD } \\
(\mathrm{cfu} / \mathrm{mL})\end{array}$ & Reference \\
\hline NMR biosensor & Milk & 2 & $10^{5}$ & Zou et al., 2019 \\
IMS-microfluidic chip & Lettuce & 3 & $10^{4}$ & Xu et al., 2015 \\
GMBN-ICTS & Milk & 20 & $5 \times 10^{5}$ & Xia et al., 2016 \\
SPR & Milk & 1 & $1.25 \times 10^{5}$ & Mazumdar et al., 2007 \\
Fluorescent sensor & Whole milk & 1 & $10^{3}$ & This study \\
\hline
\end{tabular}

${ }^{1} \mathrm{LOD}=$ limit of detection; NMR = nuclear magnetic resonance; IMS = immunomagnetic separation; GMBNICTS = gold magnetic bifunctional nanobeads; SPR = surface plasmon resonance. 


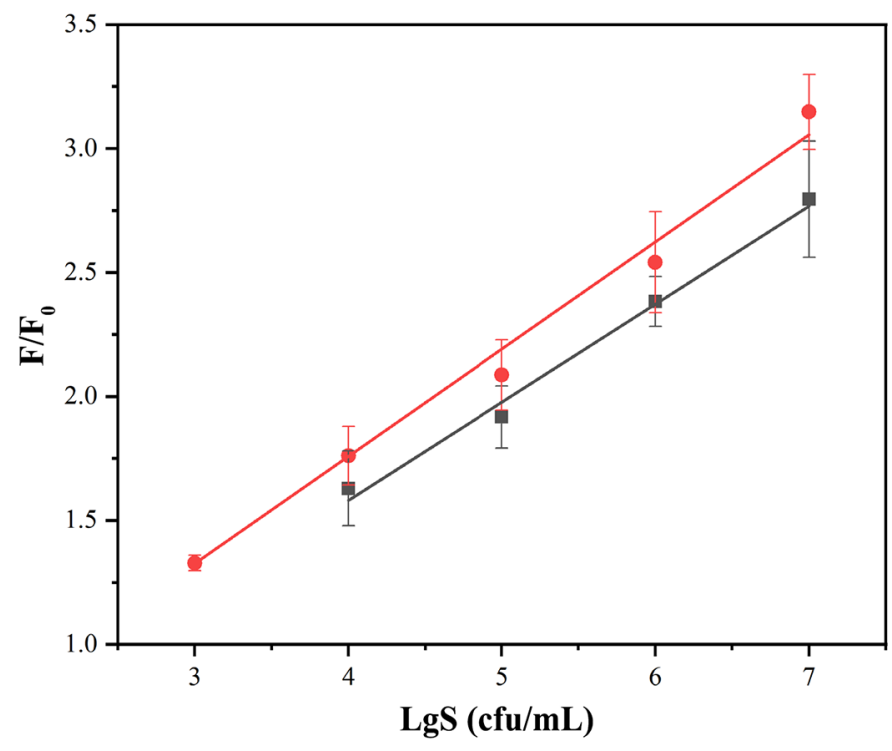

Figure 6. Sensitivity detection of Salmonella in PBS (red circles) and in whole milk (black squares). $\mathrm{F} / \mathrm{F}_{0}$ represents the relative increase in fluorescence signal $(P<0.05, \mathrm{n}=3)$.

in milk. In future work, we will directly and covalently couple the macromolecular ligand to the surface of QD as fluorescent probes and change the detection system. Such a process may enhance the sensitivity of detecting Salmonella and decrease the LOD.

\section{ACKNOWLEDGMENTS}

This research was supported by the National Natural Science Foundation of China (Beijing; 31860467). The authors have not stated any conflicts of interest.

\section{REFERENCES}

Angela, D. P., C. Giuseppina, F. V. Tony, B. Bijo, S. Fatmira, and T. Giuseppina. 2006. Detection of Mycobacterium tuberculosis complex in milk using polymerase chain reaction (PCR). Food Control 17:776-780. https://doi.org/10.1016/j.foodcont.2005.04.019.

Bano, S., M. Hayat, T. Samreen, U. Habiba, and B. Uzair. 2020. Detection of pathogenic bacteria Staphylococcus aureus and Salmonella sp. from raw milk samples of different cities of Pakistan. Nat. Sci. 12:295-306.

Bentzen, E. L., I. D. Tomlinson, J. Mason, P. Gresch, M. R. Warnement, D. Wright, E. Sanders-Bush, R. Blakely, and S. J. Rosenthal. 2005. Surface modification to reduce nonspecific binding of quantum dots in live cell assays. Bioconjug. Chem. 16:1488-1494. https://doi.org/10.1021/bc0502006.

Chen, Y., Y. Xianyu, Y. Wang, X. Zhang, R. Cha, J. Sun, and X. Jiang. 2015a. One-step detection of pathogens and viruses: combining magnetic relaxation switching and magnetic separation. ACS Nano 9:3184-3191. https://doi.org/10.1021/acsnano.5b00240.

Chen, Z., P. Li, Z. Zhang, X. Zhai, J. Liang, Q. Chen, K. Li, G. Lin, T. Liu, and Y. Wu. 2019. Ultrasensitive sensor using quantum dots-doped polystyrene nanospheres for clinical diagnostics of lowvolume serum samples. Anal. Chem. 91:5777-5785. https://doi .org/10.1021/acs.analchem.9b00010.
Chen, Z., K. Zhang, H. Yin, Q. Li, L. Wang, and Z. Liu. 2015b. Detection of Salmonella and several common Salmonella serotypes in food by loop-mediated isothermal amplification method. Food Sci. Hum. Wellness 4:75-79. https://doi.org/10.1016/j.fshw.2015 .05 .001 .

Chhalliyil, P., H. Ilves, S. A. Kazakov, S. J. Howard, B. H. Johnston, and J. Fagan. 2020. A real-time quantitative PCR method specific for detection and quantification of the first commercialized genome-edited plant. Foods 9:1245.

Chirra, H. D., T. Sexton, D. Biswal, L. B. Hersh, and J. Z. Hilt. 2011. Catalase-coupled gold nanoparticles: Comparison between the carbodiimide and biotin-streptavidin methods. Acta Biomater. 7:2865-2872. https://doi.org/10.1016/j.actbio.2011.01.003.

Duan, M., X. Xiao, Y. Huang, G. Li, S. Shan, X. Lv, H. Zhou, S. Peng, C. Liu, D. Liu, and W. Lai. 2021. Immuno-HCR based on contact quenching and fluorescence resonance energy transfer for sensitive and low background detection of Escherichia coli O157:H7. Food Chem. 334:127568. https://doi.org/10.1016/j.foodchem.2020 .127568 .

Dutta, S., T. Chowdhury, and A. Kumar Ghosh. 2020. Green synthesis of poly-L-lysine-coated sericin nanoparticles and their molecular size-dependent antibacterial activity. Colloids Surf. B Biointerfaces 188:110822. https://doi.org/10.1016/j.colsurfb.2020.110822.

Fan, F., P. Du, B. Kan, and M. Yan. 2015. The development and evaluation of a loop-mediated isothermal amplification method for the rapid detection of Salmonella enterica serovar Typhi. PLoS One 10:e0124507. https://doi.org/10.1371/journal.pone.0124507.

Feng, K., T. Li, C. Ye, X. Gao, T. Yang, X. Liang, X. Yue, S. Ding, Q. Dong, M. Yang, C. Xiong, G. Huang, and J. Zhang. 2021. A label-free electrochemical immunosensor for rapid detection of Salmonella in milk by using CoFe-MOFs-graphene modified electrode. Food Control 130:108357. https://doi.org/10.1016/j.foodcont.2021 .108357 .

Foley, S. L., and A. M. Lynne. 2008. Food animal-associated Salmonella challenges: Pathogenicity and antimicrobial resistance1. J. Anim. Sci. 86(Suppl):E173-E187. https://doi.org/10.2527/jas .2007-0447.

Guo, Q., J.-J. Han, S. Shan, D.-F. Liu, S.-S. Wu, Y.-H. Xiong, and W.-H. Lai. 2016. DNA-based hybridization chain reaction and biotin-streptavidin signal amplification for sensitive detection of Escherichia coli O157:H7 through ELISA. Biosens. Bioelectron. 86:990-995. https://doi.org/10.1016/j.bios.2016.07.049.

Hartmann, F. A., and S. E. West. 1995. Antimicrobial susceptibility profiles of multidrug-resistant Salmonella anatum isolated from horses. J. Vet. Diagn. Invest. 7:159-161. https://doi.org/10.1177/ 104063879500700128.

Jin, L., T. Li, B. Wu, T. Yang, D. Zou, X. Liang, L. Hu, G. Huang, and J. Zhang. 2020. Rapid detection of Salmonella in milk by nuclear magnetic resonance based on membrane filtration superparamagnetic nanobiosensor. Food Control 110:107011. https:// doi.org/10.1016/j.foodcont.2019.107011.

Kaewphinit, T., N. Arunrut, W. Kiatpathomchai, S. Santiwatanakul, P. Jaratsing, and K. Chansiri. 2013. Detection of Mycobacterium tuberculosis by using loop-mediated isothermal amplification combined with a lateral flow dipstick in clinical samples. BioMed Res. Int. 2013:926230. https://doi.org/10.1155/2013/926230.

Kubo, I., M. Kajiya, N. Aramaki, and S. Furutani. 2020. Detection of Salmonella enterica in egg yolk by PCR on a microfluidic disc device using immunomagnetic beads. Sensors (Basel) 20:1060. https: //doi.org/10.3390/s20041060.

Li, P., Z. Chen, B. Liu, K. Li, H. Wang, L. Lin, L. He, J. Wei, and T. Liu. 2018. Establishment of a novel homogeneous nanoparticlebased assay for sensitive procalcitonin detection of ultra low-volume serum samples. Int. J. Nanomedicine 13:5395-5404. https:// doi.org/10.2147/IJN.S173776.

Li, T., L. Jin, K. Feng, T. Yang, X. Yue, B. Wu, S. Ding, X. Liang, G. Huang, and J. Zhang. 2020. A novel low-field NMR biosensor based on dendritic superparamagnetic iron oxide nanoparticles for the rapid detection of Salmonella in milk. Lebensm. Wiss. Technol. 133:110149. https://doi.org/10.1016/j.lwt.2020.110149. 
Liébana, S., A. Lermo, S. Campoy, M. P. Cortés, S. Alegret, and M. I. Pividori. 2009. Rapid detection of Salmonella in milk by electrochemical magneto-immunosensing. Biosens. Bioelectron. 25:510-513. https://doi.org/10.1016/j.bios.2009.07.022.

Ling, X., Y. Wei, L. Zou, and S. Xu. 2014. Functionalization and dispersion of multiwalled carbon nanotubes modified with poly-llysine. Colloids Surf. A Physicochem. Eng. Asp. 443:19-26. https: //doi.org/10.1016/j.colsurfa.2013.10.053.

Liu, K., X. Yan, B. Mao, S. Wang, and L. Deng. 2016. Aptamer-based detection of Salmonella enteritidis using double signal amplification by Klenow fragment and dual fluorescence. Mikrochim. Acta 183:643-649. https://doi.org/10.1007/s00604-015-1692-4.

Majdinasab, M., A. Hayat, and J. L. Marty. 2018. Aptamer-based assays and aptasensors for detection of pathogenic bacteria in food samples. Trends Analyt. Chem. 107:60-77. https://doi.org/10 .1016/j.trac.2018.07.016.

Mazumdar, S. D., M. Hartmann, P. Kämpfer, and M. Keusgen. 2007. Rapid method for detection of Salmonella in milk by surface plasmon resonance (SPR). Biosens. Bioelectron. 22:2040-2046. https:/ /doi.org/10.1016/j.bios.2006.09.004.

Mercanoglu Taban, B., U. Ben, and S. A. Aytac. 2009. Rapid detection of Salmonella in milk by combined immunomagnetic separation-polymerase chain reaction assay. J. Dairy Sci. 92:2382-2388. https://doi.org/10.3168/jds.2008-1537.

Momin, K. M., A. A. P. Milton, S. Ghatak, S. C. Thomas, G. B. Priya, S. Das, I. Shakuntala, R. Sanjukta, K. Puro, and A. Sen. 2020. Development of a novel and rapid polymerase spiral reaction (PSR) assay to detect Salmonella in pork and pork products. Mol. Cell. Probes 50:101510. https://doi.org/10.1016/j.mcp.2020.101510.

Murasova, P., A. Kovarova, J. Kasparova, I. Brozkova, A. Hamiot, J. Pekarkova, B. Dupuy, J. Drbohlavova, Z. Bilkova, and L. Korecka. 2020. Direct culture-free electrochemical detection of Salmonella cells in milk based on quantum dots-modified nanostructured dendrons. J. Electroanal. Chem. (Lausanne) 863:114051. https://doi .org/10.1016/j.jelechem.2020.114051.

Ni, P. e., Q. Xu, Y. Yin, D. Liu, J. Zhang, Q. Wu, P. Tian, X. Shi, and D. Wang. 2018. Prevalence and characterization of Salmonella serovars isolated from farm products in Shanghai. Food Control 85:269-275. https://doi.org/10.1016/j.foodcont.2017.10.009.

Qi, X., Z. Wang, R. Lu, J. Liu, Y. Li, and Y. Chen. 2021. One-step and DNA amplification-free detection of Listeria monocytogenes in ham samples: Combining magnetic relaxation switching and DNA hybridization reaction. Food Chem. 338:127837. https://doi.org/ 10.1016/j.foodchem.2020.127837.

Sahoo, S. L., C.-H. Liu, M. Kumari, W.-C. Wu, and C.-C. Wang. 2019. Biocompatible quantum dot-antibody conjugate for cell imaging, targeting and fluorometric immunoassay: Crosslinking, characterization and applications. RSC Advances 9:32791-32803. https:// doi.org/10.1039/C9RA07352C.

Shan, C., H. Yang, D. Han, Q. Zhang, A. Ivaska, and L. Niu. 2009. Water-soluble graphene covalently functionalized by biocompatible poly-L-lysine. Langmuir 25:12030-12033. https://doi.org/10 $.1021 /$ la903265p.

Shandilya, R., N. Bunkar, R. Kumari, A. Bhargava, K. Chaudhury, I. Y. Goryacheva, and P. K. Mishra. 2021. Immuno-cytometric detection of circulating cell free methylated DNA, post-translationally modified histones and micro RNAs using semi-conducting nanocrystals. Talanta 222:121516. https://doi.org/10.1016/j.talanta .2020 .121516$.

Shao, Y., H. Duan, L. Guo, Y. Leng, W. Lai, and Y. Xiong. 2018. Quantum dot nanobead-based multiplexed immunochromatographic assay for simultaneous detection of aflatoxin B1 and zearalenone. Anal. Chim. Acta 1025:163-171. https://doi.org/10.1016/ j.aca.2018.03.041.

Singh, B. R., M. Agarwal, M. Chandra, M. Verma, G. Sharma, J. C. Verma, and V. P. Singh. 2010. Plasmid profile and drug resistance pattern of zoonotic Salmonella isolates from Indian buffaloes. J. Infect. Dev. Ctries. 4:477-483. https://doi.org/10.3855/jidc.713.

Tsen, H. Y., C.-M. Shih, P.-H. Teng, H.-Y. Chen, C.-W. Lin, C.-S. Chiou, H.-T. Wang, G. Chang, T.-Y. Chung, P.-Y. Lee, and Y.-C. Chiang. 2013. Detection of Salmonella in chicken meat by insu- lated isothermal PCR. J. Food Prot. 76:1322-1329. https://doi .org/10.4315/0362-028X.JFP-12-553.

Wang, M., J. Yang, Z. Gai, S. Huo, J. Zhu, J. Li, R. Wang, S. Xing, G. Shi, F. Shi, and L. Zhang. 2018. Comparison between digital PCR and real-time PCR in detection of Salmonella typhimurium in milk. Int. J. Food Microbiol. 266:251-256. https://doi.org/10 .1016/j.ijfoodmicro.2017.12.011.

Wang, P., A. Wang, M. M. Hassan, Q. Ouyang, H. Li, and Q. Chen. 2020. A highly sensitive upconversion nanoparticles-WS2 nanosheet sensing platform for Escherichia coli detection. Sens. Actuators B Chem. 320:128434. https://doi.org/10.1016/j.snb.2020.128434

Wen, J., H. Gou, Z. Zhan, Y. Gao, Z. Chen, J. Bai, S. Wang, K. Chen, Q. Lin, M. Liao, and J. Zhang. 2020. A rapid novel visualized loop-mediated isothermal amplification method for Salmonella detection targeting at fimW gene. Poult. Sci. 99:3637-3642. https:// doi.org/10.1016/j.psj.2020.03.045.

Wu, B., T. Yang, D. Zou, L. Jin, X. Liang, T. Li, G. Huang, and J. Zhang. 2020a. Nuclear magnetic resonance biosensor based on streptavidin-biotin system and poly-L-lysine macromolecular targeted gadolinium probe for rapid detection of Salmonella in milk. Int. Dairy J. 102:104594. https://doi.org/10.1016/j.idairyj.2019 .104594 .

Wu, W., M. Shen, X. Liu, L. Shen, X. Ke, and W. Li. 2020b. Highly sensitive fluorescence-linked immunosorbent assay based on aggregation-induced emission luminogens incorporated nanobeads. Biosens. Bioelectron. 150:111912. https://doi.org/10.1016/j.bios .2019 .111912 .

Wu, Y., M. Wu, C. Liu, Y. Tian, S. Fang, H. Yang, B. Li, and Q. Liu. 2021. Colloidal gold immunochromatographic test strips for broadspectrum detection of Salmonella. Food Control 126:108052. https: //doi.org/10.1016/j.foodcont.2021.108052.

Xia, S., Z. Yu, D. Liu, C. Xu, and W. Lai. 2016. Developing a novel immunochromatographic test strip with gold magnetic bifunctional nanobeads (GMBN) for efficient detection of Salmonella choleraesuis in milk. Food Control 59:507-512. https://doi.org/10.1016/j foodcont.2015.06.028.

Xiao, G., B. Chen, M. He, and B. Hu. 2020. Dual-mode detection of avian influenza virions (H9N2) by ICP-MS and fluorescence after quantum dot labeling with immuno-rolling circle amplification. Anal. Chim. Acta 1096:18-25. https://doi.org/10.1016/j.aca 2019.10.063.

Xiong, Y., K. Zhang, B. Gao, Y. Wu, X. Huang, W. Lai, Y. Xiong, and Y. Liu. 2019. Fluorescence immunoassay through histone-dspoly(AT)-templated copper nanoparticles as signal transductors for the sensitive detection of Salmonella choleraesuis in milk. J. Dairy Sci. 102:6047-6055. https://doi.org/10.3168/jds.2019-16472.

Xu, Y.-G., Z.-M. Liu, B.-Q. Zhang, M. Qu, C.-S. Mo, J. Luo, and S.-L. Li. 2015. Development of a novel target-enriched multiplex PCR (Tem-PCR) assay for simultaneous detection of five foodborne pathogens. Food Control 64:54-59.

Xue, L., L. Zheng, H. Zhang, X. Jin, and J. Lin. 2018. An ultrasensitive fluorescent biosensor using high gradient magnetic separation and quantum dots for fast detection of foodborne pathogenic bacteria. Sens. Actuators B Chem. 265:318-325. https://doi.org/10 $.1016 / j . s n b .2018 .03 .014$.

Yan, J. X., W. Hu, K. You, Z.-e. Ma, Y. Xu, Y. Li, and Q. He 2020a. Biosynthetic mycotoxin conjugate mimetics-mediated green strategy for multiplex mycotoxin immunochromatographic assay. J. Agric. Food Chem. 68:2193-2200. https://doi.org/10.1021/acs .jafc.9b06383.

Yan, W., L. Fan, J. Li, Y. Wang, H. Han, F. Tan, and P. Zhang. 2020b. Bimodal size distribution immuno-quantum dots for fluorescent western blotting assay with high sensitivity and extended dynamic range. Mikrochim. Acta 187:598. https://doi.org/10.1007/s00604 -020-04578-z.

Yang, L., W. Deng, C. Cheng, Y. Tan, Q. Xie, and S. Yao. 2018. Fluorescent immunoassay for the detection of pathogenic bacteria at the single-cell level using carbon dots-encapsulated breakable organosilica nanocapsule as labels. ACS Appl. Mater. Interfaces 10:3441-3448. https://doi.org/10.1021/acsami.7b18714. 
Yu, H., and P. J. Stopa. 1996. Application of an immunomagnetic assay system for detection of virulent bacteria in biological samples. Pages 297-306 in Environmental Immunochemical Methods. Vol. 646. American Chemical Society.

Yu, S., Y. Tang, M. Yan, Z. P. Aguilar, W. Lai, and H. Xu. 2019. A fluorescent cascade amplification method for sensitive detection of Salmonella based on magnetic $\mathrm{Fe}_{3} \mathrm{O}_{4}$ nanoparticles and hybridization chain reaction. Sens. Actuators B Chem. 279:31-37. https:// doi.org/10.1016/j.snb.2018.09.091.

Yue, X., J. Sun, T. Yang, Q. Dong, T. Li, S. Ding, X. Liang, K. Feng, X. Gao, M. Yang, G. Huang, and J. Zhang. 2021. Rapid detection of Salmonella in milk by a nuclear magnetic resonance biosensor based on the streptavidin-biotin system and O-carboxymethyl chitosan target gadolinium probe. J. Dairy Sci. 104:11486-11498. https://doi.org/10.3168/jds.2021-20716.

Zhang, C., Y. Han, L. Lin, N. Deng, B. Chen, and Y. Liu. 2017. Development of quantum dots-labeled antibody fluorescence immunoassays for the detection of morphine. J. Agric. Food Chem. 65:1290-1295. https://doi.org/10.1021/acs.jafc.6b05305.

Zhang, J., X. Liu, W. Shi, Y. Wei, Z. Wu, J. Li, and K. Xu. 2021. Rapid and sensitive detection of Escherichia coli O157:H7 based on silver nanocluster fluorescent probe. J. Iranian Chem. Soc. 106. https://doi.org/10.1007/s13738-021-02384-9.

Zhang, L., X. Dou, C. Zhang, G. Ying, C. Liu, J. Luo, Q. Li, P. Li, Y. Wang, and M. Yang. 2018a. Facile preparation of stable PEGfunctionalized quantum dots with glycine-enhanced photoluminescence and their application for screening of aflatoxin $\mathrm{B}_{1}$ in herbs.
Sens. Actuators B Chem. 261:188-195. https://doi.org/10.1016/j .snb.2018.01.124.

Zhang, W., Z. He, L. Yi, S. Mao, H. Li, and J.-M. Lin. 2018b. A dual-functional microfluidic chip for on-line detection of interleukin- 8 based on rolling circle amplification. Biosens. Bioelectron. 102:652-660. https://doi.org/10.1016/j.bios.2017.12.017.

Zhou, B., T. Liang, Z. Zhan, R. Liu, F. Li, and H. Xu. 2017. Rapid and simultaneous quantification of viable Escherichia coli $\mathrm{O} 157: \mathrm{H} 7$ and Salmonella spp. in milk through multiplex real-time PCR. J. Dairy Sci. 100:8804-8813. https://doi.org/10.3168/jds.2017-13362.

Zhou, J., X. Zhang, W. Qian, Q. Yang, Y. Qi, Y. Chen, and A. Wang. 2021. Quantum dots-based fluorescence immunoassay for detection of tiamulin in pork. J. Food Saf. 41:e12930.

Zou, D., L. Jin, B. Wu, L. Hu, X. Chen, G. Huang, and J. Zhang. 2019. Rapid detection of Salmonella in milk by biofunctionalised magnetic nanoparticle cluster sensor based on nuclear magnetic resonance. Int. Dairy J. 91:82-88. https://doi.org/10.1016/j.idairyj .2018.11.011.

\section{ORCIDS}

Ugur Tamer (๑) https://orcid.org/0000-0001-9989-6123

Ganhui Huang @ https://orcid.org/0000-0003-0814-3754

Jinsheng Zhang ๑ https://orcid.org/0000-0002-6616-0301 